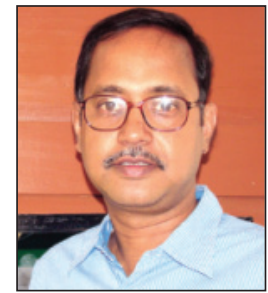

JOURNAL OF MINES, METALS \& FUELS www.jmmf.info

ff Linkedin

INDUSTRY DIRECTIONS

Jayanta Bhattacharya

Hony. Chief Editor

\title{
Doing away with blasting in underground development: a collaboration with Vale and Komatsu-CMIC
}

Come June, 2021 Vale, Komatsu and CMIC (Canada Mining Innovation Council) plan to start a major trial of Komatsu hard-rock cutting with Komatsu DynaCut Technology in Vale's Garson mine, in Sudbury, Canada - to access the McConnell orebody. The triad plan to demonstrate the ability to cut rock in excess of UCS $250 \mathrm{MPa}$; cut at a commercial rate of more than $3.5 \mathrm{~m} / \mathrm{shift}$; quantify the cost per metre of operation and start to look at the potential comparison with conventional drill and blast development; assess the health, safety and environmental suitability of the mechanical rock excavation (MRE) process; and gain insight into the potential of an optimised MRE process. Another Komatsu unit has already been assembled and is most likely operating at the Cadia underground mine in New South Wales, Australia, operated by Newcrest Mining. Vale will be watching developments here, where a three-month "pre-trial" cutting hard rock will take place.

The collaboration was necessary. There are various OEMs entering the market with hard-rock cutting equipment. All of them approach the problem a little bit differently, so it is difficult for one company to trial all of the options. At the same time, the industry is trying to leverage these new technologies and processes across the industry for a mechanical cutting type of future. For a shift from the established technology of drilling and blasting this is essential that the option offers the safety, cost and productivity benefits to make some of these new underground mines viable. Underground hard-rock cutting led development is more revolutionary and transformational in nature, so industry collaboration is even more important. CMIC's role is to bring the mine and the OEM on board protecting and furthering the interests of different stakeholders. CMIC is well connected with underground professionals and like-minded companies, and is able to pull in interest and facilitate the collaboration framework.

In 2016 and 2018, Komatsu implemented a proof of concept and, after that proof of concept, there was interest from miners to build a full commercial unit - which has happened now. The prototype was ultimately to test the enabling cutting

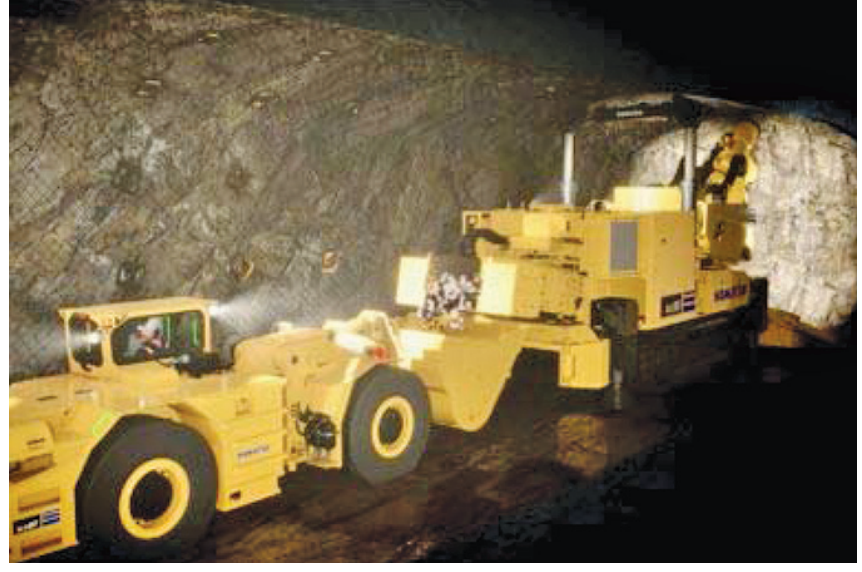

The rock cutting combine: Picture courtesy: Komatsu

technology, whereby this element was retrofitted to a mediumsized roadheader for manoeuvrability. What Komatsu has done now is fully embed it into a system more like a continuous miner, which has the cutting arm, ground handling shovel and collector and the rest of the body to put it into a full production, continuous operation. It is now going to be part of the production process, as opposed to just testing the cutting aspect. Komatsu DynaCut Technology, which, for us, is an extremely low energy process for cutting the hard rock compared to, say, a TBM. The ongoing development has the ability to integrate it with existing infrastructure within current process at the mine - bolters, trucks, LHDs, etc. It is not about fully redesigning the mine to implement this technology. To consider an undercutting technology, the aspects you need to consider are rock toughness - the ability to resist a crack when a tensile force is applied, sort of like a jackhammer - and brittleness - how much energy that rock can absorb before it breaks.

The priority for the development is to have a shallow, low stress ground environment to start off with. At the same time, these are significant machines that would have to be disassembled to go down a shaft, which would be complicated. The ramp access at Garson helped. The other point is that Garson is an operating mine so we have got the 